\title{
O estudo do imperativo no período trovadoresco
}

\author{
Gisela Sequini Favaro \\ Universidade Estadual Paulista "Júlio de Mesquita Filho" (UNESP), \\ Araraquara, São Paulo, Brasil \\ giselasfavaro@gmail.com \\ https://orcid.org/0000-0002-7321-7935
}

\section{DOI: http://dx.doi.org/10.21165/el.v47i1.1973}

\section{Resumo}

Esta pesquisa tem como objetivos principais o mapeamento e a análise das formas verbais imperativas no Português Arcaico (PA). Serão consideradas como objeto de estudo as formas do imperativo e o contexto em que estão conjugadas em PA. A metodologia para o desenvolvimento deste trabalho é constituída pela coleta e análise dos dados nas Cantigas de Santa Maria. A relevância desta pesquisa reside, principalmente, em analisar a estruturação morfológica do imperativo, ainda não estudada no que se refere à constituição verbal da época medieval.

Palavras-chave: Linguística Histórica; modo imperativo; Português Arcaico.

\section{The study of the imperative in the troubadour period}

\begin{abstract}
This research aims at mapping and analyzing the imperative verbal forms in Archaic Portuguese (AP). The corpus is composed by Alfonso X's Cantigas de Santa Maria. The relevance of this research consists in analyzing the morphological structure of imperative verbal forms that has not been studied yet regarding the verbal formation in Archaic Portuguese. The main goal is to show whether the imperative morphological structure in AP already worked as an independent mood or not, as well as helping to understand the history of the language.
\end{abstract}

Keywords: Historical Linguistics; imperative mood; Archaic Portuguese.

\section{Introdução}

O objetivo principal deste trabalho é analisar o comportamento das formas verbais do modo imperativo do Português Arcaico (doravante PA), no período conhecido por trovadoresco (fins do século XII até meados do século XIV) referente à primeira fase do período arcaico.

A partir da análise da estrutura morfológica das formas verbais imperativas em PA, pretendemos observar alguns aspectos da evolução da língua portuguesa no que se refere às mudanças que ocorrem com os verbos, em especial com o modo imperativo, focalizando nossa pesquisa no momento arcaico da língua.

A relevância do tema deste estudo reside em seu ineditismo. Apesar de existirem diversos estudos sobre o período arcaico (cf. COUTINHO, 1958; SILVA NETO, 1952; SAID ALI, 1964; MATTOS E SILVA, 1989, 2001; MAIA, 1997[1986]), não encontramos trabalhos que envolvam as mudanças morfológicas do imperativo no que se refere à constituição verbal da época medieval, na medida em que o que temos são apenas alguns comentários breves sobre a conjugação das formas verbais naquele 
período. Assim, estudando a formação das conjugações verbais da língua portuguesa em seu estágio "inicial" (ou melhor, no estágio temporal em que primeiramente começa a ser referida com este nome), poderemos contribuir para a observação de mudanças linguísticas que ocorreram na constituição do sistema verbal ao longo dos tempos.

A escolha do modo imperativo se justifica por duas razões: em primeiro lugar, existem poucos estudos que tratam da mudança morfológica sofrida no emprego das formas imperativas no PB (cf. FARACO, 1982; SCHERRE, 2002; PERINI, 1996); e, em segundo lugar, nenhum desses poucos estudos traz análises envolvendo dados da época da origem da língua portuguesa para justificar a causa e a natureza dessa mudança morfológica.

Dessa forma, pode-se dizer que há muitos estudos sobre a história dos verbos portugueses, mas poucos trabalhos específicos sobre a estrutura morfológica e o comportamento das formas verbais em PA. ${ }^{1}$ Assim, estudando a formação das conjugações verbais da língua portuguesa em seu estágio "inicial” (ou melhor, no estágio temporal em que primeiramente começa a ser referida com este nome), poderemos contribuir para a observação de mudanças linguísticas que ocorreram na constituição do sistema verbal ao longo dos anos.

\section{Breves considerações sobre o Modo Imperativo}

Faria (1958), em sua Gramática superior da Língua Latina, diz que no indoeuropeu o imperativo era usado para expressar ordem ou pedido e não proibições. Para o autor, não havia, na origem do latim, um imperativo negativo e, para suprir tal necessidade, empregava-se a partícula negativa ne anteposta ao imperativo afirmativo, ou o infinitivo presente precedido do imperativo do verbo nolo, ou, ainda, utilizava-se a forma do presente do subjuntivo precedida de uma negação. Segundo Faria (1958), as formas verbais do imperativo presente eram conjugadas apenas nas $2^{\text {as }}$ pessoas do singular e do plural. Sobre a estrutura morfológica, o autor diz que, para ser conjugado, o imperativo se valia do radical do infectum. ${ }^{2}$

Silveira Bueno (1958, p. 175) afirma que todas as formas do imperativo são encontradas na língua arcaica, isto é, "as do imperativo propriamente dito e as do supletivo $^{3}$, quando a ordem se transforma num pedido, numa simples aspiração". O autor afirma que, no período arcaico, era possível encontrar o presente do subjuntivo, o infinitivo e o futuro do indicativo em função do imperativo, como mostram os exemplos: ${ }^{4}$

(1) “Senhora, benza-vos Deus. Deus vos mantenha, senhor!”. (Gil Vicente - O Velho da Horta) mantenha: subjuntivo

(2) "Sus! Andar!" (Gil Vicente - O Velho da Horta) andar: infinitivo

(3) "E vós, alma, rezareis, contemplando as vivas dores da Senhora [...]" rezareis: futuro do indicativo. (Gil Vicente - Obras 3)

\footnotetext{
1 Ressaltamos que este estudo visa analisar as estruturas do modo imperativo a partir de suas características morfológicas (portanto, formais) e não semânticas (relativas à significação).

${ }^{2}$ Para Faria (1958), infectum é o radical dos tempos de ação incompleta.

${ }^{3}$ Silveira Bueno (1958) chama de supletivo as formas verbais do subjuntivo.

${ }^{4}$ Exemplos retirados de Silveira Bueno (1958, p. 175).
} 
Câmara Jr. (1975[1970]) afirma que, desde o latim, o subjuntivo já estava associado ao modo imperativo para expressar as ordens e as proibições. Segundo o autor, eram as formas subjuntivas que supriam as pessoas que faltavam ao imperativo afirmativo. Já no imperativo negativo, utilizado nas proibições, todas as pessoas eram formadas, obrigatoriamente, a partir do presente do subjuntivo.

O mesmo mecanismo de formação das formas verbais imperativas permaneceu no português, segundo Câmara Jr. (1975[1970]). O autor ainda diz, entretanto, que houve uma simplificação do sistema na passagem do latim para o português. No latim, distinguia-se um imperativo presente para ordens imediatas e um imperativo futuro para o que deveria ser cumprido. Hoje, no sistema do português, só temos o imperativo presente e as formas do imperativo futuro foram eliminadas.

Outro aspecto interessante abordado por Câmara Jr. (1975[1970]) é que desde o latim já existia certa fluidez entre a concepção de imperativo e a de subjuntivo como expressão de desejo. De acordo com o autor, "o uso deste por aquele era uma maneira delicada de dar uma ordem, não só no latim vulgar propriamente dito, mas ainda na linguagem culta e coloquial" (CÂMARA JR., 1975, p. 136).

Para Said Ali (1964), as formas próprias do imperativo ( $2^{\mathrm{a}}$ pessoa do singular e $2^{\mathrm{a}}$ pessoa do plural) só diferem das formas do presente do indicativo pela eliminação do -s final, por exemplo, canta, cantai, traze, trazei, etc. Já o verbo ser, segundo o autor, no português antigo apresentava a forma sei e sede, idênticas às do extinto seer (latim sedere). $\mathrm{O}$ autor ainda diz que a $2^{\mathrm{a}}$ pessoa do singular do verbo dizer apresentava em português antigo duas formas: di e dize, semelhantes ao imperativo de dicere em outras línguas românicas.

Faraco (1982) também ressalta que, no latim, as formas do imperativo afirmativo e negativo da $2^{\mathrm{a}}$ pessoa do singular eram CANTA/ NE CANTES. Segundo o autor, com o passar do tempo, a forma cantes passou a ser utilizada sem o advérbio de negação, para expressar uma ordem positiva. E para justificar esse uso, Faraco (1982) apresenta motivos pragmáticos, afirmando que seria uma espécie de reforço para garantir que a ordem dada pelo emissor fosse executada.

Coutinho (1958), em sua Gramática Histórica, assim como Câmara Jr. (1975 [1970]), diz que não passaram ao português as formas latinas do imperativo futuro. $O$ autor também afirma que, na segunda pessoa do plural, ocorreu a sonorização do $-t$ em $-d$ na passagem do latim ao português e que a queda deste operou-se, em português, no correr do século XV (COUTINHO, 1958).

Os trabalhos mais recentes (cf. PONTES, 1972; FARACO, 1982, 1986, 1996; MENON, 1984; MONTEIRO, 2002 e SCHERRE, 1998, 2002) têm voltado seus olhares para a questão do modo verbal e, em especial, o modo imperativo. De acordo com Menon (1984), por mais que em uma língua não exista o modo imperativo, isso não atesta a existência de outros recursos para exprimir ordem ou proibição. Neste caso, para se dar ordem, nem precisamos usar palavras: gestos, sinais e olhares também podem ser utilizados.

Por outro lado, Câmara Jr. (1964), em seu Dicionário de Filologia e Gramática, afirma que existem três modos distintos no português: indicativo (que indica a certeza do fato), subjuntivo (o modo da dúvida) e imperativo (quando queremos que um fato ocorra). 
A respeito do modo imperativo, Câmara Jr. (1964) diz que é utilizado para exprimir ordem, tendo relação com o presente e com o futuro. O autor ainda ressalta que as formas imperativas são apenas referentes às segundas pessoas, porém considera também a existência da terceira pessoa, devido ao que ele chama de "tratamento indireto", e a primeira pessoa do plural, pois o falante pode se inserir na ordem expressa.

O autor também explica que a correspondência das formas do imperativo com a do presente do indicativo relativas a $t u$, na perspectiva histórica, provêm do imperativo latino. A respeito dessa relação, Câmara Jr. (1964) declara ser aquele mais "agressivo" e este usado para expressar ordens de forma mais indireta.

Para Stavrou (1973, p. 93), a forma variante seria o presente do indicativo e esse uso, ao invés da forma subjuntiva, ocorre devido a "o amolecimento de formas de comando" , que é uma espécie de suavização das formas imperativas. De acordo com o autor, no PB falado não usamos mais o subjuntivo para expressar o imperativo, mas sim a forma indicativa.

Em Morfologia Portuguesa, Monteiro (2002) também faz suas considerações sobre o imperativo. O autor afirma que o imperativo ocorre somente com a $2^{\mathrm{a}}$ pessoa, seja ela do singular ou do plural, já que as ordens são dirigidas ao ouvinte, aquele com quem se fala. Outro aspecto interessante apontado por Monteiro (2002) é que as formas verbais do indicativo teriam, segundo ele, a função de expressar o imperativo. Para o autor, podemos utilizar uma forma verbal por outra, o que é bastante comum na língua portuguesa.

Vilela e Koch (2001) definem que o modo imperativo, objeto de estudo desta pesquisa, é considerado uma forma semi-conjugada, pelo fato de a maior parte das pessoas serem extraídas do subjuntivo. Segundo os autores, o valor do imperativo está pautado a toda situação comunicativa, uma vez que só pelo contexto saberíamos se está sendo usado para expressar imposição, conselho, etc.

Scherre (2002) também afirma que, quando os enunciados são dirigidos a mais de uma pessoa, a preferência é sempre pelas formas subjuntivas e não imperativas. A respeito da forma variante, a autora diz que o seu uso não acarreta nenhum tipo de problema para o falante, e a variação no uso do imperativo não distingue grupos sociais. Não existe estigma social associado ao uso do imperativo na forma indicativa ou na forma subjuntiva. As duas formas não são marcadas de prestígio e nem são usadas como estereótipos do suposto mal falar (SCHERRE, 2002).

Faraco (1982) ainda postula que a forma variante, apesar de contradizer a gramática e ser utilizada em situações informais, não é utilizada apenas por pessoas de baixa escolaridade. A variação envolve aspectos da situação, do contexto, dos objetivos do falante e do tipo de assunto.

Borges (2004) também realizou uma análise sobre formas imperativas no PB. Segundo a autora, encontramos hoje duas formas usadas para expressar a ordem no PB, relativas à segunda pessoa do singular. A primeira é considerada padrão por seguir as prescrições da Gramática Tradicional, oriunda do presente do subjuntivo (CANTE), e a segunda, considerada pela autora como forma variante, se confunde com a $2^{\mathrm{a}}$ pessoa do

\footnotetext{
5 "the softening of command forms".
} 
singular (você) do presente do indicativo (CANTA). A partir da análise dos dados, Borges (2004) conclui que essa forma denominada de variante é, na realidade, a forma indicativa, relativa à segunda pessoa você, afirmando que o imperativo não existe mais na amostra do PB como modo independente.

Portanto, como pode ser visto, os trabalhos que tratam da mudança sofrida pelas formas verbais imperativas apresentam análises envolvendo dados mais recentes da língua. Mesmo nas gramáticas históricas, só é possível notar descrições da estrutura morfológica das formas verbais imperativas e em quais contextos elas eram aplicadas. Em nenhum momento temos uma análise mais detalhada envolvendo dados do estágio inicial da língua, a fim de averiguar se a situação que encontramos hoje, em relação à dúvida quanto ao imperativo ser um modo independente ou não, já ocorria no PA.

\section{Corpus}

Para a constituição do corpus do presente trabalho, escolheu-se analisar textos poéticos remanescentes do galego-português medieval (em conformidade com as demais pesquisas desenvolvidas pelo grupo em que se insere e porque estes trazem pistas mais seguras das características prosódicas da língua do período), e um dos aspectos decisivos para a determinação dos textos a serem estudados neste trabalho foi verificar se havia registros de interação entre os interlocutores.

Como o período temporal abrangido por esta tese situa-se no século XIII, de todos os documentos remanescentes ${ }^{6}$ deste período e que chegaram até nós, através dos cancioneiros medievais, as líricas profana e mariana se enquadram no tipo de texto que favorece o uso do imperativo porque muitas vezes retratam interações entre interlocutores. Com o intuito de encontrar tais formas verbais, consideramos os textos poéticos para a observação de situações que proporcionassem diálogos, sobretudo os reproduzidos através do discurso direto, pois o uso do imperativo só ocorre em contextos de interação direta (diálogos) entre os interlocutores.

As Cantigas de Santa Maria, segundo Castro (2006) e Leão (2007), além de serem um precioso documento linguístico e uma verdadeira obra de arte, constituem uma valiosa fonte histórica da vida cotidiana e do imaginário popular de toda cultura Ibérica, na Idade Média:

Além de representarem as tranformações históricas, guardando óbvias ligações com o culto mariano, não só dão um vasto espaço ao diabo como personagem, mas também assemelham-se às catedrais na representação da diversidade populacional e das crenças fantásticas [...]. Em sua vastidão, o texto apresenta uma enorme variedade de povos

\footnotetext{
${ }^{6}$ Além dos poemas trovadorescos e das Cantigas de Santa Maria, existem outros gêneros textuais que também foram preservados ao longo dos anos. Tratam-se de arquivos jurídicos, os chamados documentos notariais, que apresentam como temas doações de terras, testamentos, compra ou venda de imóveis, inventários, etc. Há também os forais ou costumes, cujo conteúdo reúne leis locais que estabeleciam as normas disciplinares em relação aos habitantes. De acordo com Mattos e Silva (2006), estes textos são importantes para o conhecimento do português arcaico, pois são significativos e informativos, além de trazerem as datas em que foram exarados. Porém, no que concerne à riqueza ao conhecimento da sintaxe, tais textos não são valiosos, em função da estrutura formular ser muito restrita, "às vezes alatinada, natural a este tipo de texto que segue modelos da tradição jurídica latina" (MATTOS E SILVA, 2006, p. 39).
} 
(etnias, religiões, nacionalidades, classes sociais) e os mais fantásticos acontecimentos. (CASTRO, 2006, p. 43-44).

[...] elas nos falam não só da vida religiosa, mas da vida em toda a sua complexidade, constituindo talvez o mais rico documento para o conhecimento da mentalidade, dos costumes, das doenças, das profissões, da prostituição, do jogo, dos hábitos monásticos, de todos os aspectos, enfim do cotidiano medieval da Ibéria. (LEÃO, 2007, p. 153).

Neste sentido, ao lermos atentamente os textos das cantigas marianas, podemos notar a presença da língua oral destes devotos. E, segundo Leão (2007, p. 153),

O trovador, muitas vezes recorre a ditos populares, ou estes explodem à sua revelia, no texto escrito que se vai construindo. Isso sem contar que todo bom narrador - e D. Afonso é um ótimo narrador - dá um cunho de irrecusável oralidade aos seus diálogos. Há nas Cantigas de Santa Maria diálogos tão naturais que quase nos fazem ouvir as vozes dos interlocutores.

Peña (1973) também enfatiza, baseada nos estudos de Marquês de Valmar $^{7}$ (1889), que a linguagem das cantigas não era o galego popular, mas sim o galego erudito que adquiriu (sem perder a essência do dialeto português primitivo), o caráter de idioma literário. Apesar disso, como o período temporal abrangido por esta tese situa-se entre os séculos XIII e XVI, de todos os documentos remanescentes desta época e que chegaram até nós, através dos cancioneiros medievais, as líricas profana e mariana se enquadram no tipo de texto que favorece o uso das formas imperativas, uma vez que há registro de fala muito próximo ao da linguagem popular e cotidiana (tanto da corte quanto da população local), com a presença de diálogos entre as personagens, ao longo das cantigas, nos quais aparecem ordens e pedidos.

O corpus é constituído das 420 Cantigas de Santa Maria (de agora em diante, CSM) de Afonso X, a partir de edições interpretativas e fac-similadas. As CSM foram elaboradas em galego-português e atribuídas a Dom Afonso X de Castela, o Sábio, com a colaboração de trovadores, músicos, desenhistas e miniaturistas que acolhia em sua corte, tendo sido produzidas principalmente no final de sua vida, enquadrando-se na fase denominada "arcaica" do desenvolvimento do português.

\section{Fundamentação teórica}

O conceito de morfema é muito importante quando se trata de análises que abordam aspectos morfológicos. Neste trabalho, para realizar a análise dos dados encontrados, tomamos como ponto de partida a fragmentação das formas verbais em unidades mínimas portadoras de significado. Dos tipos de morfemas constituintes das formas verbais do PA estudadas, o mais recorrente é o morfema zero, já que as formas verbais imperativas coincidentes com a do presente do indicativo não possuem morfemas modos temporais, ou melhor, eles são representados pelo morfema zero que marca essa ausência.

\footnotetext{
${ }^{7}$ Crítico e filólogo do século XVIII, autor da obra Las Cantigas de Alfonso X el Sabio de 1889.
} 
Rocha (1999) afirma que, no afã de descrever as línguas, os estruturalistas chegaram ao conceito de morfema. Bloomfield (1984[1933]) diz que o morfema é uma forma recorrente (com significado) que não pode ser analisada em formas recorrentes (significativas) menores.

Para Rosa (2000), cada morfema é um átomo de som e significado, isto é, um signo mínimo. De acordo com essa perspectiva, a morfologia é o estudo desses átomos e das combinações que podem ocorrer.

Monteiro (2002) também possui uma definição para o conceito de morfema. O autor, assim como demais estudiosos, declara que morfema é a menor unidade dotada de significado. De acordo com autor, o morfema é uma unidade abstrata que, na prática, pode representar várias formas. Segundo Monteiro (2002), se observarmos as palavras vida e vital, parece claro que em ambas as ocorrências há um mesmo morfema, que se realiza como [vid] e [vit].

Ainda sobre a definição de morfemas, é importante ressaltar a existência do processo de cumulação. Para Rosa (2000), na análise morfêmica, espera-se que a um elemento de significado deva corresponder um elemento no nível da expressão e viceversa. Porém, ao propor que um único morfe possa representar a vogal temática e a desinência para TMA (cf. verbo amar conjugado na segunda pessoa do singular: am[raiz], - $a$ - [VT+ind.pres] $+-s$ [2 $\left.2^{\mathrm{a}} \mathrm{ps}\right]$ ), quebra a afirmação inicial, uma vez que um único morfe representa duas posições distintas do padrão verbal, como pode ser observado em amo ( $1^{\mathrm{a}}$ ps. presente do indicativo).

Outro conceito morfológico relevante para o desenvolvimento desta pesquisa é a distinção entre radical e tema. Segundo Monteiro (2002), observando os vocábulos portugueses, é possível verificar que geralmente terminam por uma vogal, depois da qual costumam aparecer as desinências. Nas palavras casamento, foguete e cadeira, por exemplo, após as vogais (o, e, a), temos o morfema /s/ indicativo de plural. E, segundo o autor, para identificarmos o radical de uma palavra, basta retirarmos a vogal final e tudo que aparece depois dela. Nesse caso, os radicais das palavras mencionadas são: casament-, foguet-, cadeir-.

Porém, quando o radical apresenta a vogal final, que passa a ser denominada vogal temática, o radical passa a ser conhecido por tema. Para Monteiro (2002), o tema é um tipo de radical ou radical completo, pronto para receber os morfemas próprios das categorias gramaticais. $\mathrm{O}$ autor ainda propõe que a vogal temática, por ser átona, em contato com o sufixo iniciado por vogal, sofre o processo de elisão ou crase.

Já Rocha (1999) define raiz como sendo um morfema comum a várias palavras de um mesmo grupo lexical, portador da significação básica desse grupo de palavras. Para o autor, "em claro, clarear, aclarar, esclarecer, esclarecimento e clarividência, a raiz é clar-. Em livro, livrinho, livreiro, livraria e livresco, a raiz é livr-. Em tom, tonal, tonicidade, entoar, desentoar, toado e desentoadamente, a raiz é tom, com a variante to-" (ROCHA, 1999, p. 102).

Kehdi (2003) apresenta uma opinião contrária à de Rocha (1999) e propõe que o radical corresponde ao elemento irredutível e comum às palavras da mesma família. De acordo com o autor, devemos evitar a designação de raiz, vinculada à perspectiva diacrônica, para se referir ao radical. Segundo o autor, nem sempre há coincidência entre os enfoques sincrônicos e diacrônicos, por exemplo, em comer, o radical é com- 
(cf. comida, comilão), ao passo que a raiz é ed-. A raiz é do domínio da origem histórica e o radical é do domínio da sincronia da língua (KEHDI, 2003). Os conceitos de morfema, raiz e radical são muito relevantes para o desenvolvimento das análises dos dados, pois para compreender o funcionamento das formas verbais conjugadas no modo imperativo e verificar se estávamos diante de formas variantes ou não, foi necessário realizar primeiro uma divisão morfológica dos dados.

Durante a coleta e a análise dos dados, para considerar uma forma verbal imperativa ou não, levamos em consideração a presença ou ausência de sujeito na sentença. Câmara Jr. (1975[1970]) declara que a língua portuguesa, assim como as demais línguas românicas (cf. francês, espanhol, etc.), preservou o padrão frasal básico da língua latina, que consistia num "nexo" entre "sujeito" e "predicado", segundo as nomenclaturas que as gramáticas latinas adotaram ao traduzir e acompanhar a gramaticologia grega.

Para relacionar os constituintes de um grupo frasal, é importante, segundo o autor, nos atentarmos à colocação desses elementos em relação uns aos outros. De acordo com Câmara Jr. (1975[1970]), em latim, a colocação dos termos era absolutamente livre, do ponto de vista gramatical, apesar de existirem certas construções mais usuais.

Já em português, a colocação dos constituintes não se fixou de modo tão rígido, como no francês, por exemplo, mas existe um princípio básico de ordenamento dos elementos nas frases ou orações. A respeito da ordenação do sujeito, tema abordado durante a discussão dos resultados deste artigo, Câmara Jr. (1975[1970]) propõe que sendo o sujeito tema da informação contida no predicado aparece naturalmente na primeira posição da sentença, quando não há motivações particulares condicionando outras colocações. ${ }^{8}$

A respeito da anteposição do verbo ao sujeito, Câmara Jr. (1975[1970]) afirma ser de um valor estilístico, cuja função consiste na melhor focalização da ação verbal como tema da comunicação. Neste aspecto, o autor ressalta que, na linguagem coloquial e em especial na literária, há possibilidade de inversão do sujeito, quando não existe objeto direto para opor, pela colocação, ao sujeito.

Sobre o PA, Mattos e Silva (1993), baseada nos estudos de Huber (1986), ressalta que, nesse período, a ordem direta ou "normal" (grifo da autora) é a SVC (sujeito - verbo - complemento). Além desta ordenação, existiam também outras possibilidades de colocação dos constituintes nas sentenças no período arcaico.

Ilari (2000) também traz observações interessantes sobre a constituição sintática do período latino que acabou influenciando a composição das línguas românicas. Segundo o autor, a oração do latim vulgar, com a perda dos casos, obrigou a buscar novas maneiras para indicar funções sintáticas, tarefa que passou a ser desempenhada pela ordem das palavras e pelo uso das preposições. Para o autor, foi através deste contexto que o português desenvolveu uma ordem mais fixa, em relação à existente no

\footnotetext{
${ }^{8}$ Câmara Jr. (1975[1970], p. 252) apresenta, como exemplo, o contexto do verbo dicendi intercalado ou acrescentado às palavras de outrem citadas em discurso direto (cf. a): É muito tarde - disse ele - para partirmos; b) Não desanimemos por tão pouco - aconselhou meu pai. Outro contexto também proposto pelo autor é a presença inicial de um advérbio intensivo para demarcar a importância primacial de uma circunstância (cf. a) Lá vêm eles; b) Só então chegaram os viajantes.
} 
latim, com a finalidade de distinguir, entre as expressões nominais da oração, o sujeito e o objeto direto.

Já em estudos linguísticos mais recentes acerca do $\mathrm{PB}$, podemos verificar segundo Castilho e Elias (2012), que a morfologia verbal está sendo simplificada, sendo necessário manter o sujeito na sentença, pois nem sempre é possível recuperá-lo pela morfologia do verbo. Por exemplo, a forma verbal fala pode pertencer à segunda pessoa do singular (você fala), à terceira pessoa do singular (ele fala) e ainda à primeira pessoa do plural (a gente fala).

Borges (2004), assim como outros estudiosos anteriores a ela (cf. NARO; LEMLE, 1977; FARACO, 1982; SANDMANN, 1993), também ressalta que hoje, no $\mathrm{PB}$, o sujeito nas sentenças declarativas está se tornando praticamente obrigatório, devido a uma simplificação das flexões verbais. Tomando como base estas afirmações, analisamos os contextos (função semântica) que cada forma verbal imperativa foi usada em PA, a fim de averiguar a presença ou a ausência de sujeito nos dados mapeados e se este elemento proporcionou o uso ou não de formas verbais imperativas variantes.

\title{
4 Metodologia e Análise dos Dados
}

A metodologia baseia-se no mapeamento das formas verbais do imperativo nas Cantigas de Santa Maria. Contamos também com glossários, vocabulários, dicionários, e especialmente com o glossário de Mettmann (1972), como auxílio na categorização das formas verbais. Abaixo, como ilustração, apresentam-se exemplos dos procedimentos de mapeamento dos dados nesta pesquisa:

(4)

\author{
A bõa dona se foi ben dali \\ a un' eigreja, per quant' aprendi, \\ de Santa Maria, e diss' assi: \\ "Sennor, acorre a tua coitada". (CSM 17, v. 55-58)
}

(5)

Chorando dos ollos mui de oraçon,

lle diss': "Ai Sennor, oe mi oraçon [...]”. (CSM 21, v. 15-16)

(6)

E o maestre da nave diss' a un seu ome: "Vai, coz

carn' e pescado do meu aver, que te non cost' hũa noz". (CSM 5, v. 147-148)

Após a coleta dos dados, foram analisadas as estruturas morfológicas das formas verbais imperativas encontradas, comparando-as com a estrutura morfológica das formas verbais do presente do indicativo e do subjuntivo presentes no corpus, a fim de explicar se critérios, tais como ordem, presença ou ausência do sujeito e contextos 
relacionados a atos de fala (ordem ou pedido), podem ser utilizados para considerar uma forma imperativa ou não. O exemplo a seguir representa a divisão morfológica realizada durante a análise dos dados:

(7) Verbo Acorrer $(\mathrm{PA})=$ Acordar em, resolver, decidir $(\mathrm{PB})$

Imperativo: acorre

\begin{tabular}{|l|l|l|l|}
\hline Radical & VT & MT & NP \\
\hline acorr & $e$ & $\varnothing$ & $\varnothing$ \\
\hline
\end{tabular}

Presente do Indicativo: acorres

\begin{tabular}{|l|l|l|l|}
\hline Radical & VT & MT & NP \\
\hline acorr & $e$ & $\varnothing$ & $s$ \\
\hline
\end{tabular}

Presente do Subjuntivo: acorras

\begin{tabular}{|l|l|l|l|}
\hline Radical & VT & MT & NP \\
\hline acorr & $\boldsymbol{e}$ & $a$ & $s$ \\
\hline
\end{tabular}

A coleta dos dados no corpus proporcionou o mapeamento das formas verbais do modo imperativo nas CSM, para a realização das análises. Apresentaremos nesta seção os resultados obtidos. Foram coletadas 217 formas verbais conjugadas no modo imperativo. Deste total, 175 ocorrências estão conjugadas nas $2^{\mathrm{a}} \mathrm{pp}$ e $2^{\mathrm{a}} \mathrm{ps}$. Optamos por exluir de nossas análises as ocorrências mapeadas na $3^{\mathrm{a}} \mathrm{ps}, 1^{\mathrm{a}} \mathrm{pp}$ e $3^{\mathrm{a}} \mathrm{pp}$, pois estas pessoas são todas extraídas do presente do subjuntivo, o que já favorece o uso de uma estrutura morfológica específica e bem demarcada para expressar o modo imperativo.

Entre os itens que podem auxiliar nesta investigação acerca das formas verbais imperativas, destacamos a presença ou a ausência de sujeito nas frases. Todas as ocorrências mapeadas foram analisadas e investigamos o contexto que as formas verbais estão inseridas. Nas CSM, por exemplo, foram mapeadas três ocorrências com o verbo acorrer flexionado na $2^{\mathrm{a}}$ ps. Veja abaixo as estrofes com os dados:

(9)

\footnotetext{
"Sennor, acorre a tua coitada" (CSM 16, v. 58)

E chorando e tremendo | diss': “Ai, Virgen groriosa,

acorre-m' a esta coita | tu que es tan piadosa
} 
que acorre-los coitados; | poren, Sennor preciosa,

fais que est' erro que fige | que cáia en obridança”. (CSM 303, v. 30-33)

Mais pois entrou na ygreja | daquesta Santa Reynna,

chorando muit' e dizendo: | "Se[n]or, acorre-m' aginna [...]" (CSM 357, v. 16-17) situação:

Fazendo a divisão sintática dos elementos acima, encontramos a seguinte

"Sennor, acorre a tua coitada" (CSM 16, v. 58)

Sujeito: Ø

Predicado: acorre a tua coitada

Vocativo: Sennor

E chorando e tremendo | diss': “Ai, Virgen groriosa,

acorre-m' a esta coita | tu que es tan piadosa

que acorre-los coitados; | poren, Sennor preciosa,

fais que est' erro que fige | que cáia en obridança". (CSM 303, v. 30-33)

Sujeito: Ø

Predicado: acorre-m' a esta coita

Vocativo: Ai, Virgen groriosa

Mais pois entrou na ygreja | daquesta Santa Reynna,

chorando muit' e dizendo: | "Se[n]or, acorre-m' aginna [...]” (CSM 357, v. 16-17)

Sujeito: Ø

Predicado: acorre-m' aginna [...]

Vocativo: $\operatorname{Se}[\mathrm{n}]$ nor

Levando em consideração o contexto em que os dados aparecem, há diversos elementos que nos permitem afirmar que se trata indubitavelmente de formas conjugadas no imperativo, e não de outros tempos verbais. Entre os itens que podem auxiliar nesta investigação acerca das formas verbais imperativas, destacamos a presença ou a ausência de sujeito explícito nas frases.

A ausência de sujeito é o critério crucial para afirmarmos que se trata de uma forma imperativa e não de outro modo. Para desenvolver nossas análises acerca da presença ou ausência de sujeito nas formas verbais do modo imperativo em PA, partimos de estudos desenvolvidos por linguistas (NARO; LEMLE, 1977; FARACO, 
1982, 1986; SANDMANN, 1993; BORGES, 2004 e MATTOS E SILVA, 2004) sobre o fenômeno no PB. Em seus estudos sobre a sintaxe do português, Naro e Lemle (1977, p. 1977, tradução nossa) afirmam que

$\mathrm{Na}$ fala das classes socioeconômicas mais baixas do Brasil, a regra de concordância de número entre sujeito-verbo está atualmente passando por um processo de mudança. Em estágios iniciais do idioma, como na língua padrão e das classes superiores, essa regra é categórica no sentido de que cada verbo concorda com o sujeito. Nas classes mais baixas, por outro lado, a regra está, obviamente, no caminho da extinção. ${ }^{9}$

Os autores propõem que a regra de concordância sujeito-verbo é respeitada em classes econômicas superiores, enquanto que o não cumprimento está associado ao falar de pessoas ou comunidades mais carentes.

Sobre este assunto, Sandmann (1993) também declara que as flexões de número e pessoa dos verbos foram, de modo geral, suprimidas na variante inculta. Estruturas do tipo eu trabaio, tu trabaia, você trabaiava, eles trabaiava, etc., são comuns e esse fenômeno se deve "ao seu valor não semântico e à sua função puramente gramatical, fato observável também no inglês, inclusive em sua variante culta ou formal, em que todas as pessoas são iguais, menos a $3^{\text {a }}$ do singular: I love, you love, he loves, you love, they love" 10 (SANDMANN, 1993, p. 41, tradução nossa).

Faraco (1982, p. 207, tradução nossa), assim como os demais autores, afirma que "em um tempo como o do imperfeito do indicativo, que na variedade padrão possui três formas (cantava, cantávamos, cantavam, por exemplo), na variedade rural há apenas uma (cantava)". ${ }^{11} \mathrm{O}$ autor ainda ressalta que este fenômeno está ocorrendo no $\mathrm{PB}$ e não só em dialetos rurais ou falados por pessoas de baixo poder econômico, mas de um modo geral no falar dos brasileiros, em que é possível observar que a "falta de flexão" dos verbos está acarretando a obrigatoriedade do sujeito em grande parte das frases ou orações declarativas. ${ }^{12}$

Mattos e Silva (2004) também declara que, com o aumento do uso do pronome você e da expressão a gente com funções de pronomes pessoais e com a diminuição dos pronomes $t u$ e vós, ocorreu uma generalização com a $3^{\text {a }}$ pessoa verbal. De acordo com a autora, hoje no PB encontramos um paradigma verbal de quatro formas flexionadas (eu falo, ele, você e a gente fala; nós falamos; eles e vocês falam), um outro de três posições verbais (eu falo; ele, você, a gente fala; eles e vocês falam) e por fim, em regiões rurais, áreas geodialetais e em comunidades onde há uma concentração de falantes menos escolarizados; segundo Mattos e Silva (2004), temos apenas duas posições verbais (eu falo; ele, você, a gente, eles e vocês fala). Para Mattos e Silva (2004), assim como já

\footnotetext{
9 "In the speech of the lower socio-economic classes of Brazil the rule of subject-verb number agreement is currently undergoing a process of change. In earlier stages of language, as in the standard language and upper classes, this rule is categorical in the sense that every verb agrees with the subject. In the lower classes, on the other hand, the rule is obviously well on its way to extinction".

10 "Eu amo, você ama, ele ama, vocês amam, eles amam."

11 "in a tense such as the imperfect indicative, which in the standard variant has three forms (cantava, cantávamos, cantavam, for example), in the rural variants has just one (cantava)."

12 Vale ressaltar que no português há certos tipos de frases e orações declarativas que não possuem sujeito: a) sentenças com verbos que expressam fenômenos da natureza (Choveu muito.), b) quando os verbos fazer, ser e estar indicam tempo ou fenômenos da natureza (Está frio no litoral hoje. ou São quatro horas da tarde.) e, por fim, c) em situações que o verbo haver possui o significado de existência (Há muitas pessoas na rua.).
} 
haviam proposto os demais autores, quanto mais reduzido for o paradigma flexional número-pessoa do verbo, mais necessário é o preenchimento do sujeito pronominal.

Porém, em relação aos dados mapeados em PA e, levando-se em consideração o contexto que as formas verbais foram empregradas, não foi encontrado qualquer tipo de ocorrência que trouxesse o sujeito com matriz fonológica, isto é, o sujeito com realização lexical, como demonstram os exemplos citados nos parágrafos anteriores. Ao observamos atentamente os exemplos (9) e (10), temos que a posição ocupada pelo sujeito, em PA, quando estamos diante de formas verbais imperativas, é nula. Retomando o trabalho de Mateus et al. (2003), podemos afirmar que o sujeito, nas frases imperativas, designa o ouvinte em que a morfologia desinencial do verbo remete à $2^{\text {a }}$ pessoa do discurso (cf. FAZ o dever!). As autoras ainda declaram que o sujeito também pode englobar o locutor, no caso do imperativo na primeira pessoa do plural (cf. Façamos o dever.) ou ele ainda pode ser interpretado como uma expressão nominal pré-verbal ou pós-verbal correferencial com o sujeito, mas realizada como vocativo.

A respeito do uso do vocativo em frases imperativas, Mateus et al. (1994) afirmam que este termo ocupa uma posição periférica na sentença, uma vez que não é argumento externo ou interno do sintagma verbal, e sua função é designar o alocatário. Nos dados mapeados nas CSM, o vocativo foi empregado para expressar ordem ou manifestações de desejo endereçadas à pessoa para a qual o narrador, ou seja, o eulírico, se dirige, por exemplo, a Virgem Maria, um representante do clero ou da nobreza, o indivíduo envolvido no milagre, etc., como pode ser observado nos exemplos:

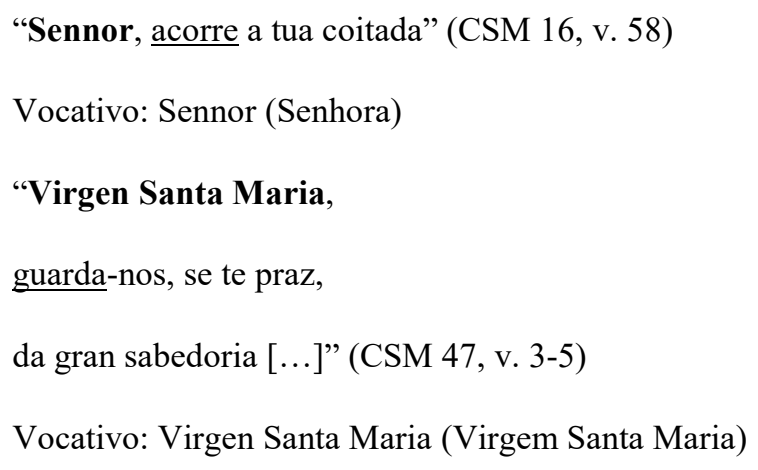

Assim, nas CSM o vocativo aparece juntamente com as formas verbais imperativas num tom apelativo e de interação entre o locutor e o alocatário, visto que as cantigas eram poemas para serem cantados em louvor à Virgem Maria, narrando os milagres e as graças alcançadas, como já foi mencionado anteriormente. Neste caso, consideramos o vocativo como uma sentença ou partícula desligada da estrutura argumentativa do verbo. A presença significativa da posição $\mathrm{VC}$ tanto da $2^{\mathrm{a}}$ ps quanto da $2^{\mathrm{a}} \mathrm{pp}$ nos reforça a hipótese de que, pelo menos nos dados relativos às CSM, há o uso do imperativo como modo, pois não há marca de sujeito com realização lexical. 


\section{Conclusão}

Com este trabalho foi possível constatar que, na época medieval, existiam duas formas diferentes para o presente e o imperativo, cada uma com sua estrutura morfológica bem demarcada. Porém, nos dias de hoje, com a substituição de $t u$ e vós por você(s), há apenas uma forma, o que pode estar ocasionando a perda da distinção do imperativo e do indicativo e subjuntivo enquanto modo.

O resultado obtido com esta pesquisa é muito relevante e nos permite uma reflexão acerca do funcionamento e do ensino de língua portuguesa no Brasil, pois há uma lacuna nos materiais didáticos presentes em muitas escolas. É comum na maioria dos casos nos depararmos com quadros canônicos que abordam conjugações direcionadas para a $2^{\mathrm{a}} \mathrm{ps}$ e a $2^{\mathrm{a}} \mathrm{pp}$ como $t u$ e vós, distantes da realidade dos falantes.

É muito habitual encontrarmos essa situação nas gramáticas escolares atuais, porém, de acordo com Cunha e Cintra (1985), esse modelo não é aplicado ao PB atual falado e escrito. Os autores consideram o pronome "você" como de tratamento de segunda pessoa do discurso, utilizada para as pessoas com quem se fala.

Faraco $\left(1982\right.$, p. 205, tradução nossa ${ }^{13}$ ), a respeito dessa mudança no paradigma verbal do PB, afirma que as formas $t u$ e vós estão se tornando obsoletas e "tratando-se do Brasil [...] podemos dizer que o paradigma normal da conjugação verbal nas gramáticas tradicionais não descreve o estado atual da língua".

Portanto, como pode ser visto, os trabalhos que tratam da mudança sofrida pelas formas verbais imperativas apresentam análises envolvendo dados mais recentes da língua. Mesmo nas gramáticas históricas, só é possível notar descrições da estrutura morfológica das formas verbais imperativas e em quais contextos elas eram aplicadas. O intuito deste estudo é preencher este espaço com explicações voltadas para a história linguística do português. No caso do modo imperativo, a temática poderia ser abordada dentro de uma perspectiva diacrônica, deixando claro para os alunos as transformações que a língua portuguesa sofreu e continua sofrendo ao longo dos tempos.

\section{REFERÊNCIAS}

ALI, M. S. Gramática Secundária e Gramática histórica da Língua Portuguesa. Brasília: Universidade de Brasília, 1964 [1931].

BLOMFIELD, L. Language. Chicago: The University of Chicago Press, 1984[1933].

BORGES, P. R. Formas verbais imperativas em tiras de jornais paulistas. 2004. $200 \mathrm{f}$. Dissertação (Mestrado em Linguística e Língua Portuguesa) - Faculdade de Ciências e Letras, Universidade Estadual Paulista "Júlio de Mesquita Filho", Araraquara, 2004.

CÂMARA, J. M. Estrutura da Língua Portuguesa. 15. ed. Rio de Janeiro: Vozes, 1975[1970].

. Dicionário de filologia e gramática referente à língua portuguesa. 4. ed. Rio de Janeiro: J. Ozon, 1964.

13 " [...] in the terms of Brazil [...] we can say that the normal paradigm of the verbal conjugation in the traditional grammars does not describe the present state of the language". 
CASTILHO, A. T.de; EliAS, V. M. Pequena Gramática do Português Brasileiro. São Paulo: Contexto, 2012.

CASTRO, B. M. As Cantigas de Santa Maria: um estilo gótico na lírica ibérica medieval. Niterói: EdUFF, 2006.

COUTINHO, I. L. Pontos de Gramática Histórica. 4. ed. Rio de Janeiro: Livraria Acadêmica, 1958.

FARACO, C. A. Norma Culta Brasileira: desatando alguns nós. São Paulo: Parábola, 2008.

Lingüistica Histórica: uma introdução ao estudo da história das línguas. v. 12. São Paulo: Parábola, 2005.

O tratamento você em português: uma abordagem histórica. Fragmenta, Curitiba, n. 13, p. 51-82, 1996.

Considerações sobre a sentença imperativa no português do Brasil. D.E.L.T.A, v. 2, n. 1, p. 1-15, 1986.

The imperative sentence in Portuguese: a semantic and historical discussion. 1982. $248 \mathrm{f}$. Tese (PhD in Modern Languages) - University of Salford, Salford, 1982.

FARIA, E. Gramática superior da Língua Latina. Rio de Janeiro: Livraria Acadêmica, 1958.

FERREIRA, M. P. The Stemma of the Marian Cantigas: Philological and Musical Evidence. In: Bulletin of the Cantigueiros de Santa Maria, Cincinnati, n. 6, p. 58-98, 1994.

FILGUEIRA VALVERDE, J. Introducción. In: ALFONSO X EL SABIO. Cantigas de Santa María: Códice Rico de El Escorial. Madrid: Castalia, 1985. p. XI-LXIII.

HUBER, J. Altportugiesiches Elementarbuch. Heidelberg, Carl Winters Universitastbuchhandlung, 1933. (Tradução Portuguesa: Gramática do Português Arcaico. Lisboa: Gulbenkian, 1986).

ILARI, R. Lingüistica Românica. 3. ed. São Paulo: Editora Ática, 2000.

KEHDI, V. Morfemas do Português. São Paulo: Ática, 2003.

LEÃO, Â. V. Cantigas de Santa Maria de Afonso X, o Sábio: aspectos culturais e literários. Belo Horizonte: Veredas \& Cenários, 2007.

MAIA, C. História do Galego-Português. 2. ed. Coimbra: Fundação Calouste Gulbenkian, Junta de Investigação Científica e Tecnológica, 1997. Reimpressão da edição do INIC, 1997[1986].

MATEUS, M. H. M.; BRITO, A. M.; DUARTE, I.; FARIA, I. H. Gramática da Língua Portuguesa. 4. ed. Lisboa: Caminho, 1994.

MATTOS E SILVA, R. V. O Português Arcaico: fonologia, morfologia e sintaxe. São Paulo: Contexto, 2006.

Editorial, 2004.

. Ensaios para uma sócio-história do português brasileiro. São Paulo: Parábola . O Português Arcaico: fonologia. São Paulo: Contexto, 2001. 
. Estruturas Trecentistas: elementos para uma gramática do português arcaico. Lisboa: Imprensa Nacional - Casa da moeda, 1989.

. O português arcaico: morfologia e sintaxe. São Paulo: Contexto, 1993.

MENON, O. P da S. O imperativo no Português do Brasil. 1984. 91 f. Dissertação (Mestrado em Letras), Universidade do Paraná, Curitiba, 1984.

METTMANN, W. Glossário. In: AFONSO X, O SÁBIO. Cantigas de Santa Maria. v. IV: Glossário. Coimbra: Universidade, 1972,

MONTEIRO, J. L. Morfologia Portuguesa. Campinas: Pontes, 2002.

NARO, A.; LEMLE, M. Syntactic diffusion. Ciência e Cultura, p. 260-268, 1977.

PEÑA, M. Affonso el Sabio. Antología com estudios preliminares y un vocabulario. México: Porrúa, 1973.

PERINI, M. A. Gramática do Português Brasileiro. 2. ed. São Paulo: Parábola Editorial, 1996.

PONTES, E. Estrutura do verbo no português coloquial. Petrópolis: Vozes, 1972.

ROCHA, L. C. A. de. Estruturas morfológicas do português. Belo Horizonte: Editora UFMG, 1999.

ROSA, M. C. Introdução à morfologia. São Paulo: Contexto, 2000.

SANDMANN, A. A linguagem da propaganda. São Paulo: Contexto, 1993.

SCHERRE, M. M. P. Uma reflexão sociolinguistica sobre o conceito de erro. In: BAGNO, M. Linguística da norma. São Paulo: Loyola, 2002.

. Sobre a influência de variáveis sociais na concordância nominal. In: SILVA, G. M. O.; SCHERRE, M. M. P. (Orgs.). Padrões sociolinguísticos: análise de fenômenos variáveis do português falado na cidade do Rio de Janeiro. Rio de Janeiro: Tempo Brasileiro, 1998.

SILVA NETO, S. História da língua portuguesa. Rio de Janeiro: Livros de Portugal, 1952.

SILVEIRA BUENO, F. Dicionário escolar da língua portuguesa. 9. ed. Rio de Janeiro: FENAME, 1975.

STAVROU, C. Portuguese pronouns and command forms. Hispanic. American Association of Teachers of Spanish and Portuguese , 1973. p. 92-93.

VILELA, M.; KOCH, I. V. Gramática da língua portuguesa: gramática da palavra, gramática da frase, gramática de texto. Coimbra: Livraria Almedina, 2001.

Recebido em: 14/09/2017

Aprovado em: 11/11/2017 